Abstract P57 Table 1 Comparison of results achieved against targets set in the London TB Metrics

\begin{tabular}{|c|c|c|c|}
\hline Metric & Metric detail & Target & Achieved \\
\hline 2 & $\begin{array}{l}\text { Access: suspected pulmonary } \\
\text { TB cases seen within } \\
2 \text { weeks of referral }\end{array}$ & $\geq 90 \%$ & $92.7 \%$ \\
\hline 3 & $\begin{array}{l}\text { Diagnosis: confirmation of } \\
\text { pulmonary TB by liquid culture }\end{array}$ & $\geq 65 \%$ & $\begin{array}{l}63.2 \% \text { ( } 70.6 \% \text { excluding } \\
\text { foreign diagnoses) }\end{array}$ \\
\hline 4 & $\begin{array}{l}\text { Diagnosis: sputum smear } \\
\text { results available within } \\
\text { one working day }\end{array}$ & $100 \%$ & $\begin{array}{l}30.1 \% \text { within } 1 \text { day, } \\
61.8 \% \text { within } 2 \text { days }\end{array}$ \\
\hline 5 & Risk assessment recorded & $\geq 90 \%$ & $94.5 \%$ \\
\hline 6 & Treatment completion rate & $\geq 85 \%$ & $\begin{array}{l}84.9 \%(98.4 \% \\
\text { excluding transfers) }\end{array}$ \\
\hline 7 & Contact tracing & $\begin{array}{l}\text { Able to report } \\
\text { activity and outcome }\end{array}$ & Achieved \\
\hline 8 & Workforce & $\begin{array}{l}\text { One TB nurse per } 40 \\
\text { notifications per year }\end{array}$ & Achieved \\
\hline 9 & HIV testing offered & $\geq 80 \%$ & $94.5 \%$ \\
\hline
\end{tabular}

Discussion We have audited performance of a local TB clinic against targets set in the London TB Metrics. Achieving a microbiological diagnosis in $65 \%$ is difficult as patients are often already on treatment before referred into the service. Changes were instituted in laboratory workflow patterns to improve sputum smear result availability within one working day, increasing to $93.8 \%$ in the first 2 months of 2010.

Conclusion The London TB Metrics targets are achievable (seven of eight targets met) and provide an audit tool that may facilitate improvements in the standard of TB care.

\section{P58 WHAT DOES PULMONARY TUBERCULOSIS (TB) LOOK LIKE IN LONDON?}

doi:10.1136/thx.2010.150979.9

C Brown, S Natas, A Salam, R Breen. Guys \& St Thomas' NHS Trust, London, UK

Introduction A typical radiological presentations of TB may lead to unnecessary and costly tests, delayed or missed diagnoses, and increased transmission. Feeling that such presentations were increasing, we retrospectively reviewed our thoracic TB patients' radiology.

Methods The London TB Register (LTBR) was queried for patients at our Trust with intrathoracic lymph node or pleural disease (January 2006-December 2008), or pulmonary disease (January 2008-December 2008). Chest radiographs (CXRs) and CT scans from symptom onset to diagnosis were analysed by a consultant radiologist. Clinical data was obtained from hospital records.

Results 118 patients were identified: male $=75$ (64\%); median age $=33$ years; HIV-infected $=10$ (8\%). 118 (100\%) had CXRs and 57 (48\%) additional CTs. From LTBR 16 had intrathoracic lymphadenopathy, 16 pleural diseases, 73 pulmonary diseases, and three mixed. One pre-diagnosis CXR was performed in 7/10 (70\%) HIVpositive and 63/108 (58\%) HIV-negative/unknown; two in 3/10 (30\%) HIV-positive, 27/108 (25\%) HIV-negative/unknown; >3 CXR (maximum eight) were performed in 18/108 (17\%) HIV-negative/ unknown. We focused on radiologically pneumonic cases. 63/118 (53\%) had consolidation on initial CXR, 66/118 (56\%) on final. 29/ 66 (44\%) had multifocal disease; all but $8 / 29$ (28\%) had either lymphadenopathy, cavitation, or nodules. $37 / 66(56 \%)$ had disease in one zone (see Abstract P58 Table 1). 18/37 (49\%) were right UZ; eight with/without pleural involvement but no other suggestive features such as cavitation or nodularity. 7/37 (19\%) were left UZ patients; $4 / 7$ (57\%) with no other suggestive features. 8/37 (22\%) had solely LZ consolidation; $2 / 8$ (25\%) with no other suggestive features. Of 17 presentations that could mimic standard pneumonia (zonal disease with/without pleural involvement but no suggestive TB features) one was HIV positive; 15 had sputum samples-4/15 $(27 \%)$ were smear positive, $12 / 15$ (80\%) were culture positive. Progression to CT was 10/17 (59\%). With any consolidation, 20/32 (63\%) CTs accessible yielded additional information, often minimal (e.g. 14/32 (44\%) showed nodules in addition to lymphadenopathy). 13/32 (41\%) were women, 9/13 (69\%) under 40-years-old.

\section{Abstract P58 Table 1}

\begin{tabular}{lclllll}
\hline Sole disease site & RUZ & RMZ & RLZ & LUZ & LMZ & LLZ \\
\hline Total number & 18 & 1 & 3 & 7 & 3 & 5 \\
With pleural involvement & 4 & 1 & 1 & 2 & 0 & 2 \\
No other TB features & 8 & 1 & 1 & 4 & 2 & 1 \\
With cavitation & 4 & 0 & 2 & 2 & 0 & 1 \\
With nodules & 0 & 0 & 0 & 0 & 0 & 2 \\
With lymphadenopathy & 9 & 1 & 2 & 0 & 1 & 2 \\
Progressed to CT & 10 & 2 & 3 & 4 & 2 & 1 \\
\hline
\end{tabular}

Discussion In our cohort the majority of patients had typical diagnostic features on presenting CXR. Lower zone cases were not uncommon but most had features suggestive of $\mathrm{TB}$. The high frequency of CT with questionable clinical gain and high radiation exposure, particularly in young women, is of concern.

\section{P59 WHY DO WE OFTEN FAIL TO MEET THE GOLD STANDARD FOR THE DIAGNOSIS OF ACTIVE TUBERCULOSIS?}

doi:10.1136/thx.2010.150979.10

S Huq, M Haris, M Gautam, P D 0 Davies. Liverpool Heart and Chest Hospital NHS Foundation Trust, Liverpool, England

Introduction Although laboratory culture of Mycobacterium tuberculosis (M TB) remains the gold standard for the diagnosis of active tuberculosis (TB), only $66 \%$ of pulmonary and $46 \%$ of extrapulmonary cases of TB in the UK are culture confirmed. ${ }^{1}$ The Health Protection Agency's Strategic Plan aims for at least 70\% of pulmonary $\mathrm{TB}$ cases to be confirmed by positive culture. The aim of this study was to identify the reasons for not obtaining culture confirmation in a cohort of active TB patients.

Methods A retrospective study of all patients with active tuberculosis in a TB centre between January and December 2009.

Results 69 patients (46 male) with a mean age of 42 years (range 3-83) were diagnosed. 36 (52\%) had pulmonary TB with or without extra-pulmonary disease and $33(48 \%)$ had extra-pulmonary TB only. $29(81 \%)$ cases of pulmonary TB were culture positive and 4 $(11 \%)$ had no growth on culture. $3(8 \%)$ cases had no sample obtained. These were all children aged $3-5$ years who had a positive Mantoux test, evidence of TB on chest radiograph and a history of close contact. $17(52 \%)$ cases of extra-pulmonary TB were culture positive. $10(30 \%)$ had samples taken but no growth on culture. 2 $(6 \%)$ had samples obtained but not sent for culture while 4 (12\%) had no sample obtained.

Conclusion The commonest reason for not obtaining culture confirmation was a negative growth (20\%). Failure to obtain a microbiological sample $(10 \%)$ and failure to send the collected sample for mycobacterial culture $(3 \%)$ were the other reasons. A positive culture of $\mathrm{MTB}$ is important because it not only confirms the diagnosis but also provides the drug susceptibility profile of the organism. Our finding that the largest proportion of cases not confirmed by positive culture was due to no growth from a specimen suggests that the current microbiological methods for growing M TB may be inadequate and further research is needed to increase the diagnostic yield. Secondly, there is a need to educate 